\title{
A NOVA AGENDA PARA O DESENVOLVIMENTO SUSTENTÁVEL
}

\section{THE NEW AGENDA TO THE SUSTAINABLE DEVELOPMENT}

\author{
Carmen Silvia Lima Arrudai
}

Resumo: Em 2015, numa decisão histórica, os Estados membros da ONU, dentre eles o Brasil, se reuniram para estabelecer os 17 objetivos de desenvolvimento sustentável como parte da Agenda 2030 para transformar nosso mundo, buscando o fortalecimento da paz universal com mais liberdade, através da erradicação da pobreza e diminuição das desigualdades. Nos próximos 15 anos os Estados trabalharam conjuntamente, numa parceria global, para alcançar as ambiciosas metas universais que visam a garantir a dignidade humana, com plena realização pessoal, protegendo o planeta da degradação, trazendo prosperidade e paz. O presente trabalho tem por objetivo examinar a evolução do desenvolvimento sustentável, com uma breve retrospectiva das Convenções Internacionais, os objetivos pactuados, 17 ODS, bem como alguns avanços já obtidos pelo Brasil.

Palavras-chave: Desenvolvimento sustentável. Agenda 2030. 17 ODS.

Abstract: In 2015, in a historic delegation, ONU's member states, including Brazil, met to establish the 17 sustainable development goals as part of Agenda 2030 to change the world, seeking to strengthen universal

\footnotetext{
i Graduada em Direito pela Universidade Federal do Rio de Janeiro (1989), Juris Doctor pela University of Miami (2008) com especialização em Direito Comparado e Arbitragem Internacional. Doutoranda em Sociologia e Direito pela UFF. Mestre pela Universidade Federal Fluminense em Justiça Administrativa e Direito Ambiental. Juíza Federal desde 1996, titular da 15ª. Vara do Rio de Janeiro, convocada para compor a $6^{\mathrm{a}}$ Turma Especializada do Tribunal Regional Federal da $2^{\mathrm{a}} \mathrm{Re}-$ gião no bienio 2013-2014. Presidente da Comissão de Direito Civil da EMARJ- Escola da Magistratura Regional Federal da $2^{a}$ Região. Procuradora do Municipio do Rio de Janeiro de 1991 a 1996.
} 
peace with freedom through eradication of poverty and reducing inequalities. Over the next 15 years, the United States has worked together in a global partnership to achieve ambitious universal goals to ensure human dignity with full personal fulfillment, protecting the planet from degradation, bringing prosperity and peace. The purpose of this paper is to examine the evolution of development, with a brief retrospective of the International Conventions, the agreed objectives, 17 ODS, as well as some changes already made by Brazil.

Keywords: Sustainable Development. 2030 Agenda. 17 ODS. 


\section{INTRODUÇÃO}

Ao embarcarmos nesta grande jornada coletiva, comprometemo-nos que ninguém será deixado para trás. ${ }^{1}$

Inauguramos o século XXI com um grande desafio: viver num mundo livre de pobreza, da fome, de doenças e de penúria, sem violência, com alfabetização universal, com acesso à saúde e à justiça, com garantia da dignidade humana, a igualdade e não discriminação, bem-estar físico e mental, através da boa governança, atingindo o crescimento econômico com desenvolvimento sustentável, com a preservação dos bens fundamentais para a sobrevivência humana, para o bem do futuro da própria humanidade.

Com efeito, o século XX foi marcado pela conscientização universal da finitude dos recursos naturais tendentes à escassez ${ }^{2}$, e que o mundo vem sofrendo as consequências adversas de desenvolvimento desenfreado, submetido a um capitalismo selvagem, sujeitando o planeta à depredação das fontes naturais, poluição do ar, dos rios e mares, desmatamento de florestas e tantas catástrofes que acarretaram por provocar o aquecimento climático, sujeitando a população mundial aos efeitos dos gases estufa, e pior, a fome e abandono de cuidados.

Assim, diante da conscientização de que o futuro da humanidade depende da garantia de acesso, a todos, dos bens vitais, considerados bens fundamentais para uma vida digna, de forma a dar concretude a proclamados direitos humanos fundamentais, foi elaborada, em setembro de 2015, pelos Estados Membros da ONU, uma "Agenda para o desenvolvimento sustentável" com 17 objetivos a serem alcançados até 2030.

Com efeito, se a Declaração Universal de Direitos Humanos de $1948^{3}$ inaugurou uma nova era de direitos, afirmando direito à dignidade da pessoa humana e à vida, (BOBBIO, 2004, p. 225) neste século compreendeu-se finalmente a necessidade de perseguir o desenvolvimento sustentável, a fim de garantir o bem-estar e vida digna das futuras gerações.

Ao longo destas décadas, diversas Convenções Internacionais e Cúpulas se sucederam, muitas inclusive sediadas no Brasil, onde foram estabelecidos pontos importantíssimos, como a necessidade de preser vação do meio ambiente equilibrado, com a compreensão de que o futuro

1 Disponível em: <https://nacoesunidas.org/wp-content/uploads/2015/10/agenda2030-pt-br.pdf> Acesso em: 4 fev. 2018.

2 "A escassez é o problema econômico central de qualquer sociedade." (PASSOS, 2012, p. 4)

3 Disponível em: <http://www.ohchr.org/EN/UDHR/Documents/UDHR Translations/por.pdf >. Acesso em: 4 fev. 2018. 
depende de um desenvolvimento sustentável, e que um não poderia existir sem o outro.

Assim, completando 70 anos da instituição das Nações Unidas, os Estados-Membros, países desenvolvidos e não desenvolvidos, pobres e ricos, perceberam que vivemos numa "casa comum" (FRANCISCO, 2015, p. 15), e precisamos da colaboração de todos para sua preservação, para que nós, habitantes, possamos, juntos, sobreviver com plena dignidade.

Somente pode-se conceber uma vida digna onde houver assegurado o usufruto dos bens comuns, como ar, água, meio ambiente; assim como o acesso aos bens vitais, que garantem a alimentação de base e medicamento indispensável para sobrevivência (FERRAJOLI, 2018, p. 220).

No presente trabalho buscaremos, no primeiro capítulo, demonstrar a evolução do conceito de desenvolvimento, a começar pela garantia do mínimo existencial; no segundo capítulo, a importância do desenvolvimento, especialmente para o Brasil, país de proporções continentais e com uma riqueza natural inigualável. No terceiro capítulo, o desenvolvimento sustentável, e os 17 objetivos para atingi-lo (17 ODS).

\section{DIREITO AO DESENVOLVIMENTO}

Conforme já acima referido, em 1986, os membros das Nações Unidas proclamaram a Declaração sobre o Direito ao Desenvolvimento ${ }^{4}$, em cujo preâmbulo foi reafirmado que "o direito ao desenvolvimento é um direito humano inalienável e que a igualdade de oportunidade para o desenvolvimento é uma prerrogativa tanto das nações quanto dos indivíduos que compõem as nações", conforme disposto no art. $1^{\circ}$ :

1. O direito ao desenvolvimento é um direito humano inalienável em virtude do qual toda pessoa humana e todos os povos estão habilitados a participar do desenvolvimento econômico, social, cultural e político, a ele contribuir e dele desfrutar, no qual todos os direitos humanos e liberdades fundamentais possam ser plenamente realizados.

2. O direito humano ao desenvolvimento também implica a plena realização do direito dos povos de autodeterminação que inclui, sujeito às disposições relevantes de ambos os Pactos Internacionais sobre Direitos Humanos, o exercício de seu direito inalienável de soberania todas as suas riquezas e recursos naturais.

4 Disponível em: <http://www.dhnet.org.br/direitos/sip/onu/spovos/lex170a.htm>. Acesso em: 20 jul. 2014. 
Percebe-se o reconhecimento do direito humano ao desenvolvimento como um direito universal, de todas as pessoas, não mais voltado apenas a uma visão individualista. Trata-se de um "direito de solidariedade" da categoria de direito de terceira geração.

Nesta mesma linha, o Pacto Internacional sobre Direitos Econômicos, Sociais e Culturais (ONU - 1996) ${ }^{5}$, ratificada pelo Brasil em 24 de janeiro em 1992, declarava que:

$\S 1$. Cada Estado Membro no presente Pacto comprometese a adotar medidas, tanto por esforço próprio como pela assistência e cooperação internacionais, principalmente nos planos econômico e técnico, até o máximo de seus recursos disponíveis, que visem a assegurar, progressivamente, por todos os meios apropriados, o pleno exercício dos direitos reconhecidos no presente Pacto, incluindo, em particular, a adoção de medidas legislativas. (Artigo $2^{\circ}$ )

\subsection{Do direito ao mínimo existencial}

Considerando o "mínimo existencial" como um direito "às condições mínimas de existência humana digna" (TORRES, 2009, p.8), não há como desassociá-lo do desenvolvimento, como meio de assegurar o gozo dos direitos fundamentais, conforme enumera Torres "educação básica, saúde preventiva, água potável, etc., e água com o mínimo ecológico (meio ambiente saudável)." (2009, p. 11)

Assim, direito ao mínimo existencial está intrinsecamente relacionado com a dignidade da pessoa humana, ou seja, a garantia das "condições mínimas, situações materiais indispensáveis à existência humana digna" (BARCELLOS, 2011, p. 247). Para Sarlet, o mínimo existencial pode ser compreendido "como todo o conjunto de prestações materiais indispensáveis para assegurar a cada pessoa uma vida condigna (portanto, saudável) [...] constituindo o núcleo essencial dos direitos fundamentais sociais, núcleo este blindado contra toda e qualquer intervenção por parte do Estado e da sociedade." (PASSOS, 2012, p. 584).

Conforme ressaltado por Sarlet (apud PASSOS, 2012, p. 564), Otto Bachof desenvolveu, em 1954, na Alemanha, a teoria do mínimo existencial, como o reconhecimento de um direito subjetivo à garantia positiva dos recursos mínimos para uma existência digna, e não apenas o direito à

5 Disponível em: <http://bioeticaediplomacia.org/wp-content/uploads/2013/12/1966-Pacto-Internacional-sobre-os-Direitos-Económicos-Sociais-e-Culturais.pdf>. Acesso em: 12 nov. 2014 
liberdade, mas à segurança social, pois sem os recursos materiais para uma existência digna, a própria dignidade ficaria sacrificada. Aplicando a teoria então desenvolvida, a Corte Constitucional alemã consagrou definitivamente, com status constitucional, a garantia do mínimo existencial como garantia a uma existência digna que abrange mais do que a garantia à mera sobrevivência física, situando-se, portanto, além do limite da pobreza absoluta, ainda segundo Sarlet (apud PASSOS, 2012, p. 567).

No Brasil, diz-se que "mínimo existencial e o núcleo material do Princípio da dignidade humana descrevem o mesmo fenômeno" (BARCELLOS, 2011, p. 247). Torres esclarece:

a proteção do mínimo existencial, sendo pré-constitucional, está ancorada na ética, e se funda na liberdade, ou melhor, nas condições iniciais para o exercício da liberdade, na ideia de felicidade, nos direitos humanos e nos princípios da igualdade e da dignidade humana. (TORRES, 2009, p. 13).

Neste sentido, afirmou o Supremo Tribunal Federal, verbis:

A noção de mínimo existencial, que resulta, por implicitude, de determinados preceitos constitucionais (CF, art. $1^{\circ}, \mathrm{III}$, e art. $3^{\circ}, \mathrm{III}$ ), compreende um complexo de prerrogativas cuja concretização revela-se capaz de garantir condições adequadas de existência digna, em ordem a assegurar, à pessoa, acesso efetivo ao direito geral de liberdade e, também, a prestações positivas originárias do Estado, viabilizadoras da plena fruição de direitos sociais básicos, tais como o direito à educação, o direito à proteção integral da criança e do adolescente, o direito à saúde, o direito à assistência social, o direito à moradia, o direito à alimentação e o direito à segurança. ${ }^{6}$

Quanto ao conteúdo, o STJ vem alargando sua extensão, para acoIher o 'direito à educação' como direito fundamental a ser efetivado pelo Estado, segundo a teoria do mínimo existencial. Neste sentido, colhe-se do aresto proferido o seguinte trecho:

O mínimo existencial não se resume ao mínimo vital, ou seja, o mínimo para viver. O conteúdo daquilo que seja o mínimo existencial abrange também as condições socioculturais,

6 Disponível em: <http://redir.stf.jus.br/paginadorpub/paginador.jsp?docTP=AC\&doclD=627428>. Acesso em: 12 nov. 2014. 
que, para além daquestão da mera sobrevivência, asseguram ao indivíduo um mínimo de inserção na vida social. (BRASIL, 2010).

\subsection{Desenvolvimento nacional como prioridade do Brasil}

Um dos objetivos fundamentais da República Brasileira, insculpidos no art. $3^{\circ}$ do texto constitucional, é o "desenvolvimento nacional", ao lado dos demais objetivos elencados?. Desta forma, "o papel que o Estado tem a desempenhar na perseguição da realização do desenvolvimento, na aliança que sela com o setor privado, é de resto, primordial." (GRAU, 2010, p. 218)

Trata-se de "princípio constitucional impositivo, segundo CANOTILHO, OU DIRETRIZ (DWORKIN) - norma-objeto - dotado de caráter constitucionalmente conformador" (GRAU, 2010, p. 217), podendo ainda ser tido como uma 'norma constitucional programática', na lição de Barroso (2009, p. 202), "pois traça fins sociais a serem alcançados pela atuação futura dos poderes públicos". Nelas estão especificadas as metas que o governo deve buscar atender para atingir os objetivos sociais do Estado Brasileiro, em especial sua capacidade de geração e de distribuição das riquezas no âmbito da sociedade (BARROS, 2009, p. 128).

Não é tarefa fácil definir o conceito de "desenvolvimento", pressupondo dinâmicas mutações, a realizar na sociedade "um processo de mobilidade social contínua e intermitente" que "deve levar a um salto, de uma estrutura social para outra, acompanhado da elevação do nível econômico e do nível cultural-intelectual comunitário." (GRAU, 2010, p. 218)

A 'Declaração sobre o Direito ao Desenvolvimento', aprovada pela Resolução n 41/128 da Assembleia Geral das Nações Unidas, de 4 de dezembro de 1986, propõe um conceito de "desenvolvimento", como sendo

um processo econômico, social, cultural e político abrangente, que visa o constante incremento do bem-estar de toda a população e de todos os indivíduos com base em sua participação ativa, livre e significativa no desenvolvimento e na distribuição justa dos benefícios daí resultantes ${ }^{8}$.

\footnotetext{
7 Título I. "Art. $3^{\circ}$ Constituem objetivos fundamentais da República Federativa do Brasil:

I - construir uma sociedade livre, justa e solidária;

II - garantir o desenvolvimento nacional;

III - erradicar a pobreza e a marginalização e reduzir as desigualdades sociais e regionais;

IV - promover o bem de todos, sem preconceitos de origem, raça, sexo, cor, idade e quaisquer outras formas de discriminação." (BRASIL, 1988).

8 Disponível em: <http://www.dhnet.org.br/direitos/sip/africa/banjul.htm>. Acesso em: 20 jul. 2014.
} 
Trata-se de um princípio amplo, aberto, a comportar um semnúmero de predicados e adjetivos. Pode-se pretender referir-se ao desenvolvimento econômico, desenvolvimento social, desenvolvimento sustentável, desenvolvimento político, desenvolvimento humano, enfim tudo que caracterize o "fazer crescer [...] que progrida, aumente, melhore, se adiante" (FERREIRA, 1986).

Cada um desses predicados deve voltar-se, no entanto, para um objetivo especifico: "desenvolvimento humano", definido "como um processo de ampliação das escolhas das pessoas para que elas tenham capacidades e oportunidades para serem aquilo que desejam ser"9. $O$ foco deve estar no ser humano, suas oportunidades e sua qualidade de vida, a partir de três parâmetros: renda, educação e saúde.

Por outro lado, temos o desenvolvimento econômico, que leva em conta o crescimento econômico e a capacidade de gerar riqueza de um país. Este pode ser entendido como o "processo pelo qual países menos desenvolvidos elevam seu produto per capta, melhorando a qualidade de vida da população ao longo do tempo." (PASSOS, 2012, p. 654). No entanto, sendo este um dos objetivos do Estado Brasileiro a ser perseguido pelo Governo legalmente constituído, através de projetos e fórmulas elaborados por sua equipe econômica, deve-se estar atento aos princípios constitucionais que, especialmente tratam da ordem econômica, elencados no art. 170 do texto constitucional, dentre eles a defesa do meio ambiente. ${ }^{10}$

Desta forma, pode-se afirmar que, para alcançar o desenvolvimento econômico, busca-se crescimento econômico como forma de meIhoria da qualidade de vida da sua população. Existem, todavia, algumas

9 Disponível em: <http://www.pnud.org.br/IDH/DesenvolvimentoHumano.aspx?indiceAccordion=0\&li= li DH >. Acesso em: 19 jul. 2014.

10 Título VII, Capítulo I. "Art. 170. A ordem econômica, fundada na valorização do trabalho humano e na livre iniciativa, tem por fim assegurar a todos existência digna, conforme os ditames da justiça social, observados os seguintes princípios:

I - soberania nacional;

II - propriedade privada;

III - função social da propriedade;

IV - livre concorrência;

$\mathrm{V}$ - defesa do consumidor;

$\mathrm{VI}$ - defesa do meio ambiente, inclusive mediante tratamento diferenciado conforme o impacto ambiental dos produtos e serviços e de seus processos de elaboração e prestação;

VII - redução das desigualdades regionais e sociais;

VIII - busca do pleno emprego;

IX - tratamento favorecido para as empresas de pequeno porte constituídas sob as leis brasileiras e que tenham sua sede e administração no País." (BRASIL, 1988). 
precondições para o desenvolvimento, como a distribuição geográfica da nação, "as condições climáticas, e seus recursos hídricos utilizáveis além dos recursos naturais disponíveis (depósitos de petróleo e minério, por exemplo)." (PASSOS, 2012, p. 554)

As fórmulas para obter crescimento são definidas pelos economistas. Segundo Passos (2012),

economia é a ciência social que estuda como as pessoas e a sociedade decidem empregar recursos escassos, que poderiam ter utilização alternativa na produção de bens e serviços de modo a distribuí-los entre as várias pessoas e grupos da sociedade, a fim de satisfazer as necessidades humanas. (PASSOS, 2012, p. 5).

Diversos são os indicadores do desenvolvimento econômico, dentre eles, a renda per capita; o nível de estoque de capital per capita; taxas de natalidade e de mortalidade; taxa de mortalidade infantil, esperança de vida ao nascer; índice de analfabetismo e padrões educacionais; taxa de desemprego e produtividade da mão de obra; distribuição de renda; participação do setor primário no produto nacional; porcentual da população atuando na agricultura; potencial científico e tecnológico; grau de dependência externa; condições sanitárias; taxa de poupança per capita. (PASSOS, 2012, p. 554)

O Brasil é um país com uma população de 200 milhões de habitantes, com renda nacional bruta per capita de 10.260 dólares e produto interno bruto de 1,571,980 milhão de dólares (PASSOS, 2012, p. 559), considerado o $5^{\circ}$ país do mundo em extensão territorial e população, o sétimo em Produto Interno Bruto. No entanto, 21,4\% de sua população está abaixo do nível de pobreza, com níveis insustentáveis de violência contra a mulher.

Isto significa dizer que o Brasil é considerado um país em desenvolvimento, enfrentando sérias dificuldades para o seu crescimento como, por exemplo, sua extensão territorial, a falta de estradas em condições adequadas e deficiência de transportes, o isolamento social, cultural e econômico, além do desperdício de recursos.

Assim, o País vê-se obrigado a produzir cada vez mais, para possibilitar o incremento das exportações, de forma a garantir um superávit na balança comercial. Todavia, a produção em excesso acarreta o "comprometimento de estoques de serviços ecossistêmicos. O equilíbrio entre extrair e cuidar é o cerne da dificuldade de viabilizar políticas ambientais 
que conjuguem ou compatibilizem preservação com retorno econômico." (WALDMAN; ELIAS, 2013)

Obviamente que suas riquezas não são infinitas, e "a sociedade não dispõe de recursos produtivos em quantidade suficiente para produzir tudo o que a população deseja" (PASSOS, 2012, p. 47), podendo haver escassez no seu consumo e extração. Sendo assim, impõe-se perquirir acerca das políticas públicas a serem desenvolvidas pelo Estado Brasileiro de forma a garantir um crescimento econômico que preserve nossas riquezas naturais para as gerações futuras, tais como o petróleo, a mata atlântica, as reservas hídricas, as reservas minerais, e a biodiversidade.

No uso de suas atribuições constitucionais, o Governo Federal vem traçando os planos de desenvolvimento para o país, baseado em

um modelo de desenvolvimento econômico e social que combina crescimento da economia com distribuição de renda e proporciona a diminuição da pobreza e a inclusão de milhões de brasileiros e brasileiras no mercado formal de trabalho ${ }^{11}$.

A título de ilustração, vale mencionar que, desde 2007, com o Governo do Presidente Lula, foi lançado o PAC - Programa de Aceleração do Crescimento, com o objetivo de aumentar a oferta de empregos e geração de renda, elevando o investimento público e privado em obras fundamentais. Em 2011, iniciou-se a segunda fase do PAC, com os mesmos objetivos, mas buscando mais recursos e parcerias com os Estados e Municípios.

O Programa de Aceleramento do Crescimento tem por objetivo o planejamento e execução de obras de infraestrutura social, urbana, logística e energética, buscando-se um crescimento acelerado de forma sustentável. A preocupação ambiental norteia o programa, ao deixar claro que

tal desenvolvimento econômico deve beneficiar a todos os brasileiros e brasileiras e respeitar o meio ambiente. O desafio da política econômica do governo federal é aproveitar o momento histórico favorável do país e estimular o crescimento do PIB e do emprego, intensificando ainda mais a inclusão social e a melhora na distribuição de renda ${ }^{12}$.

11 Disponível em: <http://www.pac.gov.br/sobre-o-pac/medidas>. Acesso em: 20 jul. 2014.

12 Disponívelem:<http://www.planejamento.gov.br/secretarias/upload/Arquivos/ spi/PPA/2012/mensagem_presidencial_ppa.pdf>. Acesso em: 20 jul. 2014. 
No mesmo sentido o Supremo Tribunal Federal já havia definido, em acórdão de lavra do Ministro Eros Grau, que desenvolvimento, é "não apenas o crescimento econômico, mas, sobretudo elevação do nível cultural-intelectual comunitário e um processo, ativo, de mudança social." (GRAU, 1981).

Em outra oportunidade, como "guardião da Constituição"13, o Tribunal Pleno do Supremo Tribunal afirmou que o "desenvolvimento nacional" a que se referiu o texto constitucional não pode ser um desenvolvimento desenfreado e predatório, mas "tão ecologicamente equilibrado quanto humanizado" (BRASIL, 2009).

Cumpre, por fim, destacar que as Nações Unidas reconheceram expressamente no art. $2^{\circ}$, item 3 da Declaração do Direito ao Desenvolvimento ${ }^{14}$, que os Estados

têm o direito e o dever de formular políticas nacionais adequadas para o desenvolvimento, que visem o constante aprimoramento do bem-estar de toda a população e de todos os indivíduos, com base em sua participação ativa, livre e significativa no desenvolvimento e na distribuição equitativa dos benefícios daí resultantes.

O direito ao desenvolvimento econômico social e cultural foi igualmente reafirmado no art. 22 da Carta Africana de Direitos Humanos e dos Povos ${ }^{15}$, estabelecendo que "todos os povos têm direito ao seu desenvolvimento econômico, social e cultural, no estrito respeito da sua liberdade e da sua identidade e ao gozo igual do patrimônio comum da humanidade."

Em que pesem as afirmações das Cartas Universais acerca da soberania nacional para gerenciamento das riquezas naturais dos países, é inegável a disputa travada entre os países do hemisfério norte e os países em desenvolvimento do hemisfério sul, acerca das políticas de desenvolvimento sustentável.

De um lado, os países, já desenvolvidos e ricos, pretendendo estabelecer medidas mais drásticas de respeito e proteção ao meio ambiente. De outro, os países do hemisfério sul, subdesenvolvidos ou em desenvolvimento, defendendo políticas de desenvolvimento, a justificar a

13 Título IV. Capítulo III. Seção II. "Art. 102. Compete ao Supremo Tribunal Federal, precipuamente, a guarda da Constituição, cabendo-Ihe: [...]". (BRASIL, 1988).

14 Disponível em: <http://www.dhnet.org.br/direitos/sip/onu/spovos/lex170a.htm>. Acesso em: 20 jul. 2014.

15 Disponível em: <http://www.dhnet.org.br/direitos/sip/africa/banjul.htm>. Acesso em: 20 jul. 2014. 
utilização de indústrias e técnicas por vezes mais poluentes e agressivas ao meio ambiente, em prol do progresso que ainda almejavam atingir, visando à erradicação da pobreza. (SAMPAIO, 2011, p. 77)

Em outras palavras, o que se pretende é a compatibilização das necessidades dos países do terceiro mundo para atingir um nível de produtividade que garanta aos seus cidadãos níveis mínimos de dignidade humana, ainda que para tanto precisem se utilizar de tecnologia mais agressiva ao meio ambiente. Este foi o "conflito de interesses entre países do norte e países do sul", pois os países em desenvolvimento não aceitavam restrições ambientais aos seus respectivos processos de industrialização. (SAMPAIO, 2011, p. 10)

O direito a estabelecer as prioridades de desenvolvimento dos países em desenvolvimento foi exaustivamente tratado na Convenção de Paris, constando do texto do Acordo

Tendo em conta os imperativos de uma transição justa da força de trabalho e a criação de trabalho decente e empregos de qualidade, de acordo com as prioridades de desenvolvimento nacionalmente definidas,

Reconhecendo que a mudança do clima é uma preocupação comum da humanidade, as Partes deverão, ao adotar medidas para enfrentar a mudança do clima, respeitar, promover e considerar suas respectivas obrigações em matéria de direitos humanos, direito à saúde, direitos dos povos indígenas, comunidades locais, migrantes, crianças, pessoas com deficiência e pessoas em situação de vulnerabilidade e o direito ao desenvolvimento, bem como a igualdade de gênero, o empoderamento das mulheres e a equidade intergeracional ${ }^{16}$

\section{EVOLUÇÃO DO DESENVOLVIMENTO SUSTENTÁVEL}

Desenvolvimento sustentável é o "desenvolvimento que satisfaz as necessidades presentes, sem comprometer a capacidade das gerações futuras de suprir suas próprias necessidades", conforme concebido no Relatório de Brundtland, o 'Nosso Futuro Comum' (Our Common Future), publicado em $1987 .{ }^{17}$

16 Disponível em: <http://www.mma.gov.br/images/arquivos/clima/convencao/indc/Acordo_Paris. pdf>. Acesso em: 21 mar. 2014.

17 Disponível em: <http://www.onu.org.br/a-onu-em-acao/a-onu-e-o-meio-ambiente/>. Acesso em: 21 mar. 2014. 
O 'princípio do desenvolvimento sustentável' foi desenvolvido, inicialmente, na Conferência de Estocolmo de 1972, e repetido inúmeras vezes nas Conferências mundiais que se sucederam, segundo o qual se baseia a noção da necessidade da coexistência harmônica do desenvolvimento econômico com os limites ambientais, para que estes não se esgotem, mas que fiquem preservados para as futuras gerações.

Seguiu-se então a Conferência das Nações Unidas sobre Meio Ambiente e Desenvolvimento, conhecida como Rio 92. Dez anos após, foi realizada em Johannesburgo a Conferência sobre Desenvolvimento, para avaliar os avanços da Rio 92, os quais, aliás, não foram muitos.

Segundo Fiorillo (2007, p. 29), o princípio do desenvolvimento sustentável encontra fundamento no art. 225, caput, do texto constitucional ${ }^{18}$, assim como no art. 170, VI ${ }^{19}$, que trata da "Ordem Econômica e Financeira".

O Supremo Tribunal Federal, há quase uma década, já reconhece o "princípio do desenvolvimento sustentável como fator de obtenção do justo equilíbrio entre as exigências da economia e as da ecologia". Assim, o desenvolvimento nacional não pode dar-se sem levar em consideração a questão ambiental. Do voto condutor da lavra do Ministro Celso de Mello, no leading case, ADI 3549 MC/DF, colhe-se o seguinte trecho:

\section{[...]}

O PRINCÍPIO DO DESENVOLVIMENTO SUSTENTÁVEL COMO FATOR DE OBTENÇÃO DO JUSTO EQUILÍBRIO ENTRE AS EXIGÊNCIAS DA ECONOMIA E AS DA ECOLOGIA. - O princípio do desenvolvimento sustentável, além de impregnado de caráter eminentemente constitucional, encontra suporte legitimador em compromissos internacionais assumidos peloEstado brasileiro e representa fator de obtenção do justo equilíbrio entre as exigências da economia e as da ecologia, subordinada, no entanto, a invocação desse postulado, quando ocorrente situação

18 Título VIII, Capítulo VI. Art. 225. "Todos têm direito ao meio ambiente ecologicamente equilibrado, [...] impondo-se ao Poder Publico e à coletividade o dever de defendê-lo e preservá-lo para as presentes e futuras gerações." (BRASIL, 1988).

19 Título VII, Capítulo I. "Art. 170. A ordem econômica, fundada na valorização do trabalho humano e na livre iniciativa, tem por fim assegurar a todos existência digna, conforme os ditames da justiça social, observados os seguintes princípios:

$[\ldots]$

$\mathrm{VI}$ - defesa do meio ambiente, inclusive mediante tratamento diferenciado conforme o impacto ambiental dos produtos e serviços e de seus processos de elaboração e prestação." (BRASIL, 1988). 
de conflito entre valores constitucionais relevantes, a uma condição inafastável, cuja observância não comprometa nem esvazie o conteúdo essencial de um dos mais significativos direitos fundamentais: o direito à preservação do meio ambiente, que traduz bem de uso comum da generalidade das pessoas, a ser resguardado em favor das presentes e futuras gerações.

[...] (BRASIL, 2005).

Mais recentemente, em 2009, a Suprema Corte teve a oportunidade de revisitar o tema do 'desenvolvimento sustentável', ao acolher parcialmente a 'Arguição de Descumprimento de Preceito Fundamental', fulcrado nos artigos 170, 196 e 225 da Constituição Federal, onde se questionava a constitucionalidade dos atos normativos proibitivos de importação de pneus usados.

Nesta ocasião, o STF, em voto da lavra da E. Ministra Carmen Lúcia, decidiu pela proibição das futuras importações, em atendimento aos princípios constitucionais, relacionados à saúde e ao meio ambiente ecologicamente equilibrado, especialmente o desenvolvimento sustentável. Ressaltou, na própria ementa do julgado, o conceito de desenvolvimento sustentável, como sendo o

crescimento econômico com garantia paralela e superiormente respeitada da saúde da população, cujos direitos devem ser observados em face das necessidades atuais e daquelas previsíveis e a serem prevenidas para garantia e respeito às gerações futuras. (BRASIL, 2012)

\subsection{Princípios do desenvolvimento sustentável}

De acordo com a ONU, acatando a elaboração da International Law Association, o desenvolvimento sustentável estaria baseado em sete princípios, descritos na Declaração de Princípios do Desenvolvimento Sustentável de Nova Deli, elaborada em $2002^{20}$, dentre eles, o princípio do uso sustentável dos recursos naturais; da equidade e erradicação da pobreza; das responsabilidades comuns, mas diferenciadas; da precaução; do acesso à informação, participação e acesso à justiça em sede ambiental; da boa governança; e, finalmente, princípio da integração dos direitos do homem com os objetivos sociais, econômicos e ambientais.

20 Disponível em: <http://cisdl.org/tribunals/pdf/NewDelhiDeclaration.pdf>. Acesso em: 10 abr. 2014. 
Dentre estes princípios, importante destacar alguns reputados mais importantes:

\section{a) Princípio do uso sustentável dos recursos naturais}

As necessidades humanas a serem satisfeitas através de consumo são infinitas e ilimitadas enquanto que os recursos são finitos e insuficientes para a produção de bens e serviços demandados. Isto, segundo Passos, caracteriza o fenômeno da escassez, que é a preocupação básica da economia. E "somente devido à escassez de recursos em relação às ilimitadas necessidades humanas é que se justifica a preocupação de utilizá-los da forma mais racional e eficiente possível." (PASSOS, 2012, p. 4)

Toda teoria econômica de desenvolvimento está baseada na utilização dos recursos naturais como elementos essenciais no processo de desenvolvimento. Todo processo de geração de riqueza precisa, dentre outros elementos, de matéria prima, que se extrai da natureza.

O reconhecimento da necessidade de se compatibilizar o desenvolvimento econômico com o cuidado com o meio ambiente é dever de todos os países, especialmente o Brasil, país tão agraciado por riquezas naturais, muitas dos quais, por força de disposição expressa do texto constitucional ${ }^{21}$, são considerados bens da União. Lembre-se, ainda, que o Brasil dispõe de uma riqueza hídrica incomparável, com cerca de 13,7\% de toda água doce do planeta, distribuída irregularmente, no solo e subsolo do território nacional.

21 Título III, Capítulo II. "Art. 20. São bens da União:

I - os que atualmente Ihe pertencem e os que lhe vierem a ser atribuídos;

II - as terras devolutas indispensáveis à defesa das fronteiras, das fortificações e construções militares, das vias federais de comunicação e à preservação ambiental, definidas em lei;

III - os lagos, rios e quaisquer correntes de água em terrenos de seu domínio, ou que banhem mais de um Estado, sirvam de limites com outros países, ou se estendam a território estrangeiro ou dele provenham, bem como os terrenos marginais e as praias fluviais;

IV as ilhas fluviais e lacustres nas zonas limítrofes com outros países; as praias marítimas; as ilhas oceânicas e as costeiras, excluídas, destas, as que contenham a sede de Municípios, exceto aquelas áreas afetadas ao serviço público e a unidade ambiental federal, e as referidas no art. 26, Il; (Redação dada pela Emenda Constitucional $n^{\circ} 46$, de 2005)

$\checkmark$ - os recursos naturais da plataforma continental e da zona econômica exclusiva;

$\mathrm{VI}$ - o mar territorial;

VII - os terrenos de marinha e seus acrescidos;

VIII - os potenciais de energia hidráulica;

IX - os recursos minerais, inclusive os do subsolo;

$X$ - as cavidades naturais subterrâneas e os sítios arqueológicos e pré-históricos;

XI - as terras tradicionalmente ocupadas pelos índios." (BRASIL, 1988). 


\section{b) Princípio das responsabilidades comuns, porém diferenciadas}

Este princípio pode ser extraído do princípio da igualdade onde se reconhece a necessidade de dar tratamento diferenciado aos países, em razão de suas capacidades, à luz das diferentes circunstâncias nacionais, que são evidentemente diferentes, ou seja, reconhece-se as diferenças entre os países desenvolvidos e em desenvolvimento, e se estabelece responsabilidades diferenciadas para cada um, respeitadas suas capacidades e circunstâncias nacionais, com efetiva contribuição financeira anual dos países desenvolvidos em favor dos países em desenvolvimento.

\section{c) Princípio do acesso à informação}

O direito de acesso aos documentos tem origem no art. 14 da Declaração dos Direitos do Homem de 1789, 22 que garantia o direito do cidadão de verificar a necessidade da contribuição pública, e consenti-la livremente. $O$ "direito à informação", por sua vez, veio a ser expressamente erigido a direito humano universal na Declaração Universal dos Direitos Humanos (DUDH) de 1948, ${ }^{23}$ como resultante de uma convergência de entendimento entre todos os países signatários da citada Declaração, vinculante e, portanto, de observância imperativa por parte da comunidade internacional.

A Convenção Americana sobre Direitos Humanos (CADH), Pacto de San Jose da Costa Rica, de 1969, do qual o Brasil é signatário, prevê expressamente que "Toda pessoa tem direito à liberdade de pensamento e de expressão. Esse direito compreende a liberdade de buscar, receber e difundir informações e ideias de toda natureza", conforme a redação do art. $13,{ }^{24}$ contendo dois aspectos: um relacionado ao direito individual

22 ORGANIZAÇÃO DAS NAÇÕES UNIDAS. Declaração dos Direitos do Homem e do Cidadão, de 26 de agosto de 1789. "Art. 14. Todos os cidadãos têm direito de verificar, por si ou pelos seus representantes, da necessidade da contribuição pública, de consenti-la livremente, de observar o seu emprego e de lhe fixar a repartição, a coleta, a cobrança e a duração."

23 ORGANIZAÇÃO DAS NAÇÕES UNIDAS. Declaração Universal dos Direitos Humanos, de 10 de dezembro de 1948. "Art. 19. Todo o indivíduo tem direito à liberdade de opinião e de expressão, o que implica o direito de não ser inquietado pelas suas opiniões e o de procurar, receber e difundir, sem consideração de fronteiras, informações e ideias por qualquer meio de expressão."

24 ORGANIZAÇÃO DOS ESTADOS AMERICANOS. Convenção Americana Sobre Direitos Humanos, Costa Rica, 22 de novembro de 1969. "Art. 13 - Liberdade de pensamento e de expressão: 1. Toda pessoa tem direito à liberdade de pensamento e de expressão. Esse direito compreende a liberdade de buscar, receber e difundir informações e ideias de toda natureza, sem consideração de fronteiras, verbalmente ou por escrito, ou em forma impressa ou artística, ou por qualquer outro processo de sua escolha." 
que toda pessoa tem de expressar-se de forma livre sem qualquer impedimento, e outro relacionado ao direito coletivo de acesso a qualquer tipo de informação.

Posteriormente os Estados americanos participantes da Organização dos Estados Americanos (OEA), dentre eles o Brasil, presentes na Conferência de Lima, em 2001, assumiram formalmente o compromisso com a "democracia representativa", ao assinarem a "Carta Democrática Interamericana", que afirma ser este regime de governo essencial para o desenvolvimento social, político e econômico dos povos das Américas, de onde se destaca o art. $4^{\circ}$, que trata da transparência das atividades governamentais como componente fundamental ao exercício da democracia.

\section{d) Princípio da boa governança}

Das políticas públicas - De acordo com o princípio da boa governança, um governo é considerado "bom" e "democrático" se as instituições e os processos do país forem transparentes. A boa governança significa a promoção da igualdade, a participação, o pluralismo, a transparência, a responsabilidade e o Estado de Direito, de forma efetiva, eficiente e duradoura, segundo definido pelas Organizações das Nações Unidas. ${ }^{25}$

\section{TRANSFORMANDO O NOSSO MUNDO: AGENDA 2030 PARA O DESENVOLVIMENTO SUSTENTÁVEL}

Durante a Cúpula das Nações Unidas, de 2015, em Nova York, foi aprovada a Resolução da Assembleia Geral das Nações Unidas A/RES/70/1, chamada "Transformando Nosso Mundo: a Agenda 2030 para o Desenvolvimento Sustentável", onde foram definidos os 17 Objetivos Globais para o Desenvolvimento Sustentável (ODS), integradas e indivisíveis, a serem implementados pelos países, numa ação conjunta, até $2030^{26}$, sendo eles:

Objetivo 1. Acabar com a pobreza em todas as suas formas, em todos os lugares

Objetivo 2. Acabar com a fome, alcançar a segurança alimentar e melhoria da nutrição e promover a agricultura sustentável

25 Disponível em: <http://www.tce.se.gov.br/sgw/upload/3c0978352cd42924dcaa5b4773c2a334f37f16c0.pdf>. Acesso em: 10 abr. 2014.

26 Disponível em: <https://nacoesunidas.org/pos2015/agenda2030/>. Acesso em: 4 fev. 2018. 
Objetivo 3. Assegurar uma vida saudável e promover o bemestar para todos, em todas as idades

Objetivo 4. Assegurar a educação inclusiva e equitativa e de qualidade, e promover oportunidades de aprendizagem ao longo da vida para todos

Objetivo 5. Alcançar a igualdade de gênero e empoderar todas as mulheres e meninas

Objetivo 6. Assegurar a disponibilidade e gestão sustentável da água e saneamento para todos

Objetivo 7. Assegurar o acesso confiável, sustentável, moderno e a preço acessível à energia para todos

Objetivo 8. Promover o crescimento econômico sustentado, inclusivo e sustentável, emprego pleno e produtivo e trabalho decente para todos

Objetivo 9. Construir infraestruturas resilientes, promover a industrialização inclusiva e sustentável e fomentar a inovação

Objetivo 10. Reduzir a desigualdade dentro dos países e entre eles Objetivo 11. Tornar as cidades e os assentamentos humanos inclusivos, seguros, resilientes e sustentáveis

Objetivo 12. Assegurar padrões de produção e de consumo sustentáveis

Objetivo 13. Tomar medidas urgentes para combater a mudança climática e seus impactos

Objetivo 14. Conservação e uso sustentável dos oceanos, dos mares e dos recursos marinhos para o desenvolvimento sustentável

Objetivo 15. Proteger, recuperar e promover o uso sustentável dos ecossistemas terrestres, gerir de forma sustentável as florestas, combater a desertificação, deter e reverter a degradação da terra e deter a perda de biodiversidade

Objetivo 16. Promover sociedades pacíficas e inclusivas para o desenvolvimento sustentável, proporcionar o acesso à justiça para todos e construir instituições eficazes, responsáveis e inclusivas em todos os níveis

Objetivo 17. Fortalecer os meios de implementação e revitalizar a parceria global para o desenvolvimento sustentável 
O Brasil, como país em desenvolvimento, tem papel "protagonista no cenário ambiental do mundo" (MARCOVITCH, 2016, p. 17), e no cumprimento de muitas das metas na busca do desenvolvimento sustentável, por se tratar de um país de dimensões continentais e uma riqueza natural incomparável.

Assim, importantes centros universitários de pesquisa nacionais (MARCOVITCH. 2016), juntamente com o Programa das Nações Unidas para o Meio Ambiente (PNUMA) ${ }^{27}$, estão se dedicando a monitorar o cumprimento das metas estabelecidas nesses 17 objetivos. Analisando alguns dos estudos realizados, passaremos a detalhar os esforços para cumprimento dos objetivos estabelecidos.

\subsection{Objetivo 1: Acabar com a pobreza em todas as suas formas, em todos os lugares}

Fazendo expressa referência às metas a serem atingidas até 2030, o IBGE divulgou, no ano de 2017, os resultados de estudos e pesquisas sobre as condições de vida da população brasileira, considerando sua heterogeneidade e as informações demográficas e socioeconômicas colhidas, utilizando como fonte a Pesquisa Nacional por Amostra de Domicilio Contínua - PNAD, de 2012 a $2016^{28}$.

Neste estudo, foi analisada a desigualdade social existente no Brasil, a partir de importantes índices, demonstrando que o Brasil é um dos países com maior desigualdade de renda na América Latina, "região do planeta onde a desigualdade é mais pronunciada". Diversos gráficos indicam que a desigualdade varia no território, atingindo a população dividida entre cor ou raça, sendo que os menores rendimentos são percebidos por pessoas pretas ou pardas, enquanto que maior rendimento são obtidos pelos brancos.

Busca-se a erradicação da pobreza, considerada como privação de bens mínimos necessários para sobrevivência. No Brasil, ao contrário de outros países, não há uma linha oficial de corte para definição de pobreza, mas algumas linhas foram estabelecidas a partir dos programas governamentais, como Programa Brasil sem Miséria, - PBSM - que considera o valor de $R \$ 85,00$, em 2016 , pobreza extrema e, $R \$ 170,00$, pobreza.

27 Disponívelem: <http://www.br.undp.org/content/brazil/pt/home/presscenter/articles/2018/01/05/ brasil-avan-a-na-implementa-o-da-agenda-2030.html>. Acesso em: 4 fev. 2018.

28 Disponível em: < https://biblioteca.ibge.gov.br/visualizacao/livros/liv101459.pdf>. Acesso em: 4 fev. 2018. 
Outra linha utilizada como parâmetro é a do Benefício de Prestação Continuada-BCN - que equivale a $1 / 4$ do salário mínimo para fins de recebimento de benefício previdenciário para viverem e envelhecerem com dignidade (BRASIL, 1993).

Esses estudos levados a cabo pelo IBGE demonstram, em 2016, que $6,5 \%$ dos moradores de domicílios permanentes estavam na pobreza extrema", levando em consideração o valor atualmente estimados de 1,9 dólares por dia de renda ou consumo per capita, sendo que quase a metade concentrada na região Nordeste do país.

É grande o desafio a ser alcançado, pois a erradicação da pobreza está intimamente ligada à desigualdade, especialmente de cor e de raça, à falta de acesso à educação, e à dimensão territorial do Brasil e sua divisão.

\subsection{Objetivo 5: Alcançar a igualdade de gênero e empoderar todas as mulheres e meninas}

O objetivo $\mathrm{n}^{\circ} 5$ exige o enfrentamento de questões como a paridade de gêneros na esfera pública e privada, considerando-a como componente do princípio da legalidade; o equilíbrio de gêneros como forma de permitir uma igualdade real, e não apenas formal; a elaboração de políticas que permitam a compatibilização do trabalho e maternidade, considerando que a participação das mulheres no mercado de trabalho ainda é cerca de 30 pontos percentuais menor que a dos homens, segundo a Organização Internacional do Trabalho (OIT).

Diversas medidas concretas vêm sendo adotadas visando ao ingresso de mulheres no mercado de trabalho, destacando-se a recém criada Coalizão Internacional pela Igualdade Salarial (EPIC), na cidade do Panamá, em janeiro de 2018, cujo objetivo é mobilizar diversos atores em diferentes países para reduzir a desigualdade salarial entre mulheres e homens, que é cerca de $15 \%$ na região, em janeiro deste ano ${ }^{29}$.

A começar pela estimativa populacional por gênero, publicada pelo IBGE, o Brasil tem hoje uma população de 208.658.782 milhões de pessoas $^{30}$. Pela análise dos dados colhidos em 2010, verifica-se que $51,03 \%$

29 Disponível em: <http://www.ilo.org/brasilia/noticias/WCMS 616494/lang--pt/index.htm>. Acesso em 4 fev. 2018.

30 Disponível em: <https://www.ibge.gov.br/estatisticas-novoportal/sociais/populacao/9103-estimativas-de-populacao.html?\&t=destaques $>$. Acesso em: 4 fev. 2018. 
da população era composta por mulheres, contra 48,95\% de homens ${ }^{31}$. Os gráficos já indicam um número maior de mulheres com escolaridade, em relação aos homens, nas faixas etárias acima de 11 anos $^{32}$.

Assim, segundo Soares, "O Brasil já superou o gargalo da educação, porque hoje as mulheres são mais escolarizadas do que os homens, mas isso ainda não está refletindo no mercado de trabalho". Com efeito, de acordo com os gráficos do Instituto de Pesquisas, a maioria dos trabalhadores ainda é composta por homens e, do total de trabalhadores homens, $65,2 \%$ tem carteira assinada, enquanto que $62,2 \%$ das mulheres tem carteira assinada ${ }^{33}$. O rendimento médio dos homens é superior ao das mulheres ${ }^{34}$. Por outro lado, a responsabilidade pelos afazeres domésticos ainda é da mulher que, em razão da sobrecarrega, busca por jornada de trabalho mais flexível ${ }^{35}$.

Por outro lado, destaque deve ser dado à questão da violência contra as mulheres, no Brasil. Pelas estatísticas divulgadas pelo Fórum de Segurança, as mulheres são as maiores vítimas de violência sexual, com 1 estupro a cada 11 minutos ${ }^{36}$.

A violência contra as mulheres se tornou tamanha e tão expressiva que acarretou o acionamento de organismos internacionais, sendo finalmente promulgada a Lei Maria da Penha, Lei 11.340/2006, com o objetivo de coibir a violência doméstica e familiar, de natureza física, psicológica, sexual, patrimonial ou moral dirigida conscientemente contra a mulher, nos termos do art. $226 \S 8^{\circ}$ da CF/88, da Convenção sobre a Eliminação de Todas as Formas de Discriminação contra as Mulheres e da Convenção Interamericana para Prevenir, Punir e Erradicar a Violência contra a Mulher.

31 Disponível em: <https://brasilemsintese.ibge.gov.br/populacao/distribuicao-da-populacao-porsexo.html>. Acesso em: 4 fev. 2018.

32 Disponível em: <https://brasilemsintese.ibge.gov.br/educacao/anos-de-estudo-e-sexo.html>. Acesso em: 4 fev. 2018.

33 Disponível em: <https://brasilemsintese.ibge.gov.br/trabalho/categoria-do-emprego-e-sexo. html>. Acesso em: 4 fev. 2018.

34 Disponível em: <https://brasilemsintese.ibge.gov.br/trabalho/rendimento-de-todos-os-trabalhos. html>. Acesso em: 4 fev. 2018.

35 SOARES, Barbara Cobo, em entrevista para Revista Retratos. Disponível em: <https://agenciadenoticias.ibge.gov.br/agencia-noticias/2012-agencia-de-noticias/noticias/17064-retratos-ods-5-alcancar -a-igualdade-de-genero-e-empoderar-todas-as-mulheres-e-meninas.html>. Acesso em: 4 fev. 2018. 36 Disponível em: <http://www.forumseguranca.org.br/estatisticas/introducao/>. Acesso em: 4 fev. 2018. 
Nesta sequência veio a alteração do Código Penal, através da Lei 13.103/2015, que prevê o feminicídio ${ }^{37}$, homicídio praticado contra a mulher por razões da condição de sexo feminino, e incluído no rol dos crimes hediondos.

Ainda na esfera pública, percebe-se grande discriminação contra as mulheres, visto que sua participação no Poder Judiciário é de menos de $30 \%$, de acordo com levantamento realizado pelo $\mathrm{CNJ}^{38}$, sendo que a maior participação ainda está concentrada no $1^{\circ}$ grau de jurisdição, havendo diversos Tribunais que não têm sequer uma mulher compondo a Corte.

\subsection{Objetivo 13: Acordo de Paris sobre mudanças climáticas}

De forma a dar início ao cumprimento dos objetivos estabelecidos na meta 13 foi celebrado, ainda no final do ano de 2015 o Acordo de Paris $^{39}$, o qual foi ratificado pelo Brasil em setembro de 2016, por meio do Decreto Legislativo $n^{\circ}$. 140/201640, visando a estabelecer um esforço global à ameaça das mudanças climáticas.

Este acordo já vem sendo considerado um pacto histórico, por trazer a proposta de verdadeira mudança de atitude dos países ${ }^{41}$, consagrando o "princípio das responsabilidades comuns, porém diferenciadas e respectivas capacidades, à luz das diferentes circunstâncias nacionais", ao reconhecer as diferenças entre os países desenvolvidos e em desenvolvimento, e estabelecendo responsabilidades diferenciadas a cada um, respeitadas suas capacidades e circunstâncias nacionais, com uma efetiva contribuição financeira anual dos países desenvolvidos em favor dos países em desenvolvimento.

Com efeito, logo no art. $6^{\circ}$ já se vê expressa referência à promoção do desenvolvimento sustentável, integridade ambiental e transparência como corolário da boa governança, enquanto que o artigo $7^{\circ}$ trata das

37 Disponível em: <http://www.planalto.gov.br/CCIVIL_03/Ato2015-2018/2015/Lei/L13104.htm>. Acesso em: 4 fev. 2018.

38 Disponível em: <http://ajufe.org.br/imprensa/noticias/10398-comissao-ajufe-mulheres-revela-o -perfil-da-magistrada-brasileira-a-jornalistas>. Acesso em 4 fev 2018.

39 Disponível em: <https://nacoesunidas.org/wp-content/uploads/2016/04/Acordo-de-Paris.pdf. Acesso em: 22 mar. 2017.

40 Disponível em: <http://www2.camara.leg.br/legin/fed/decleg/2016/decretolegislativo-140-16-agosto-2016-783505-publicacaooriginal-150960-pl.html>. Acesso em: 22 mar. 2017.

41 Disponível em: <http://envirocenter.yale.edu/transparency-the-backbone-of-the-Paris-Agreement>. Acesso em: 22 mar. 2017. 
ações de adaptação, que devem seguir uma abordagem orientada em nível nacional, sensível a gênero, participativa e plenamente transparente, levando em consideração os grupos vulneráveis, comunidades locais e ecossistemas.

O artigo $9^{\circ}$ estabelece a obrigação dos países desenvolvidos de fornecer recursos financeiros para auxiliar os países em desenvolvimento e, ainda, de assumir a liderança na mobilização de financiamento climático. Em contrapartida, os países desenvolvidos devem prestar informações transparentes e consistentes de tal apoio aos países em desenvolvimento.

O artigo 12, por sua vez, dispõe que as partes devem cooperar para tomar medidas, conforme apropriado, para ampliar a educação, a formação, a sensibilização do público, a participação e acesso do público à informação sobre as mudanças climáticas.

\subsection{Objetivo 15: Proteger, recuperar e promover o uso sustentável dos ecossistemas terrestres, gerir de forma sustentável as florestas, combater a desertificação, deter e reverter a degradação da terra e deter a perda de biodiversidade}

Em estudo desenvolvido na USP/SP, verificou-se a situação das práticas e projetos brasileiros em relação à Floresta Amazônica, com o objetivo de preservar as Unidades de Conservação (UCs). Segundo este estudo, o Brasil possui a segunda maior cobertura florestal do mundo, perdendo apenas para a Rússia, e a maior em extensão de florestas tropicais. Sua área equivale a 516 milhões de hectares (Mha), dos quais 56\% (290 Mha) são florestas públicas. Deste total, 325 Mha correspondem à Amazônia, sendo que $91,6 \%$ correspondem a florestas públicas presentes em nove estados brasileiros, sendo eles: Acre, Amazonas, Roraima, Amapá, Pará, Maranhão, Tocantins, Rondônia e Mato Grosso.

Dados do relatório do Programa das Nações Unidas para o Meio Ambiente (PNUMA), revelam que o Brasil obteve uma queda de $36 \%$ na taxa de desmatamento na Floresta Amazônica, entre os anos de 2005 e 2009 (UNEP, 2016). Segundo relatório do Instituto do Homem e Meio Ambiente da Amazônia - IMAZON de janeiro de 2016, o desmatamento na Amazônia Legal identificado neste período foi de $52 \mathrm{~km}^{2}$, o que representa uma redução de $82 \%$ em relação ao mesmo intervalo de 2015 (quando o desmatamento alcançou $288 \mathrm{~km}^{2}$ ) (IMAZON, 2016). 
O Brasil pretende restaurar e reflorestar 12 milhões de hectares de Áreas de Preservação Permanente nos biomas Amazônia, Cerrado e Mata Atlântica até 2030, demonstrando uma grande preocupação do governo com a questão do desmatamento das florestas. (CREDIDIO, 2017, p. 163). Estes projetos têm um importante caráter pedagógico, envolvendo as comunidades locais e ONGs, e envolve enormes investimentos financeiros.

\section{CONCLUSÃO}

Na oportunidade em que se celebram os 70 anos da Declaração Universal de Direitos Humanos de 1948, percebe-se que são muitos os desafios a serem enfrentados pelos países, numa ação global, para possibilitar a perfeita integração da humanidade, permitindo o acesso aos bens vitais essenciais a uma vida digna.

Deve-se reconhecer que vivemos ainda numa época onde é enorme a desigualdade entre os homens e que, para muitos, a dignidade ainda é um sonho a ser perseguido, diante da escassez de comida, de acesso à água potável, de remédios, de escolaridade, de moradia, enfim, de um conjunto mínimo de bens fundamentais, sem os quais não se pode considerar uma existência digna.

Sem que haja a provisão mínima dos bens vitais e mais básicos de subsistência, acentuam-se as desigualdades, tanto entre ricos e pobres, como entre homens e mulheres, entre raças e cor e, em consequência, aumentam-se os níveis de insegurança e de violência.

Ao participar da Cúpula do Clima e assinar a agenda 2013 para o Desenvolvimento Sustentável, os Estados membros, inclusive o Brasil, se comprometeram a cumprir metas de desenvolvimento que tenham um impacto direto na melhoria das condições de vida da população mais carente, com investimento em educação, saúde, meio ambiente e infraestrutura.

Somente através da firme determinação de elaboração e desenvolvimento de políticas públicas, a nível federal, estadual e municipal, com a plena participação da sociedade civil, e setor privado, e por meio de ações integradas, o Brasil, como Estado Democrático de Direito que é, conseguirá colaborar para alcançar as metas estabelecidas para a plena concretização dos direitos humanos fundamentais, a prosperidade e da paz universal com mais liberdade. 


\section{REFERÊNCIAS}

BARCELLOS, Ana Paula. A eficácia jurídica dos princípios constitucionais: o princípio da dignidade da pessoa humana. 3 ed. rev. atual. Rio de Janeiro: Renovar, 2011.

BARROSO, Luís Roberto. Curso de Direito Constitucional contemporâneo: os conceitos fundamentais e construção do novo modelo. São Paulo: Saraiva, 2009.

BOBBIO, Norberto. A era dos direitos. Rio de Janeiro: Elsevier, 2004.

BRASIL. Constituição (1988). Constituição da República Federativa do Brasil. Disponível em: <http://www.planalto.gov.br/ccivil_03/constituicao/constituicaocompilado.htm>. Acesso em: 30 maio 2018.

BRASIL. Lei 8.742, de 7 de dezembro de 1993. Dispõe sobre a organização da Assistência Social e dá outras providências. Disponível em: <http:// www.planalto.gov.br/ccivil_03/Leis//8742.htm >. Acesso em: 30 maio 2018.

BRASIL. Superior Tribunal de Justiça. Recurso Especial $n^{\circ}$ 1.185.474/SC. Brasília, 20 de abril de 2010. Relator: Ministro Humberto Martins. Diário de Justiça Eletrônico, 29 mar. 2010. Disponível em: <http://www.mp.go. gov.br/portalweb/hp/42/docs/recurso_especial_1185474_stj.pdf >. Acesso em: 30 maio 2018.

BRASIL. Supremo Tribunal Federal. Medida cautelar na ação direta de inconstitucionalidade n ADI 3540 MC/DF. Brasília, DF, 01 de setembro de 2005. Disponívelem:<http://www.stf.jus.br/portal/jurisprudencia/listarJurisprudencia.asp?s1=\%28\%22desenvolvimento + nacional\%22\%29\&base= baseAcordaos\&url=http://tinyurl.com/calsslf>. Acesso em: 20 jul. 2014.

BRASIL. Supremo Tribunal Federal. Tribunal Pleno. Argüição de descumprimento de preceito fundamental no 101/DF. Brasília, 24 de junho de 2009. Relatora: Ministra Carmen Lúcia. Diário de Justiça Eletrônico, n. 108, 4 jun. 2012. Ementário n 2654-1. Disponível em: < http://redir.stf. jus.br/paginadorpub/paginador.jsp?docTP $=A C \& d o c \mid D=629955>$. Acesso em: 30 maio 2018. 
BRASIL. Supremo Tribunal Federal. Tribunal Pleno. Petição $\mathbf{n}^{\circ} \mathbf{3 3 8 8} / \mathbf{R R}$. Brasília, 19 de março de 2009. Relator: Ministro Carlos Britto. Diário de Justiça Eletrônico, n. 181, 25 set. 2009. Disponível em: <www.agu.gov.br/ page/download/index/id/1563215> . Acesso em: 30 maio 2018.

CREDIDIO, Guilherme Simões. Governança e reflorestamento: o Projeto Ciência Cidadã (ODS 15) In: MARCOVITCH, Jacques (Org.). Os Compromissos de Paris e os ODS 2030: energia, florestas e redução de GEE. São Paulo: FEA/USP, 2016. Disponível em: <https://www.usp.br/mudarfuturo/ $\mathrm{cms} />$. Acesso em 4 de mai. 2018

FERRAJOLI, Luigi. Manifesto per I'uguaglianza. Roma: Laterza, 2018.

FERREIRA, Aurélio Buarque de Holanda. Novo dicionário Aurélio da Língua Portuguesa. 2. ed. rev. Rio de Janeiro: Nova Fronteira, 1986.

FIORILLO, Celso Antônio Pacheco. Curso de Direito Ambiental Brasi -leiro. 8. ed. São Paulo: Saraiva, 2007.

FRANCISCO, Papa. Carta Encíclica Laudato Si: sobre o cuidado da casa comum. São Paulo: Paulinas, 2015.

GRAU, Eros Roberto. Elementos de Direito Econômico. São Paulo: Revista dos Tribunais, 1981.

A Ordem Econômica na Constituição de 1988: interpretação e crítica. 14. ed., rev. e atual. São Paulo: Malheiros Editores, 2010.

IBGE. Coordenação de População e Indicadores Sociais. Síntese de indicadores sociais: uma análise das condições de vida da população brasileira 2016. Rio de Janeiro, 2016. Disponível em: <https://biblioteca.ibge.gov. br/visualizacao/livros/liv98965.pdf>. Acesso em: 4 fev. 2018.

MARCOVITCH, Jacques (Org.). Os Compromissos de Paris e os ODS 2030: energia, florestas e redução de GEE. São Paulo: FEA/USP, 2016. Disponível em: <https://www.usp.br/mudarfuturo/cms/> . Acesso em 4 de mai. 2018.

PASSOS, Carlos Roberto Martins; NOGAMI, Otto. Princípios de Economia. 6. ed. rev. São Paulo: Cengage Learning, 2012. 
SAMPAIO, Rômulo Silveira da Rocha. Direito Ambiental doutrina e casos práticos. Rio de Janeiro: Elsevier, 2011.

SOARES, Barbara Cobo, em entrevista para Revista Retratos. Disponível em: <https://agenciadenoticias.ibge.gov.br/agencia-noticias/2012-agencia-de-noticias/noticias/17064-retratos-ods-5-alcancar-a-igualdade-degenero-e-empoderar-todas-as-mulheres-e-meninas.html>. Acesso em: 4 fev. 2018.

TORRES, Ricardo Lobo. O Direito ao Mínimo Existencial. Rio de Janeiro: Renovar. 2009.

WALDMAN, Ricardo Libel; ELIAS Luiz Augusto de Veiga. Os Princípios do Direito Ambiental e o Pagamento por Serviços Ambientais / Ecossistêmicos (PSA/PSE). Revista de Direito Ambiental, São Paulo, v. 18, n. 69, p. 53-83, jan./mar. 2013. 